\title{
Sjögren's, Renal Tubular Acidosis And Osteomalacia - An Asian Indian Series
}

\author{
Pulukool Sandhya ${ }^{*}, 1$, Debashish Danda ${ }^{1}$, Simon Rajaratnam ${ }^{2}$ and Nihal Thomas ${ }^{2}$ \\ ${ }^{I}$ Department of Clinical Immunology and Rheumatology, Christian Medical College and Hospital, Vellore-632004, \\ India \\ ${ }^{2}$ Department of Endocrinology, Diabetes and Metabolism, Christian Medical College and Hospital, Vellore-632004, \\ India
}

\begin{abstract}
Objective: To study the profile of Renal Tubular Acidosis (RTA) in Asian Indian patients with Primary Sjögren's Syndrome (pSS).

Methods: The Electronic medical records of patients with a diagnosis of pSS seen between 2003 and 2010 at our tertiary care teaching hospital were screened for RTA. Clinical features, immunological profile, acid-base balance and electrolyte status, 25-hydroxyvitamin D $(25(\mathrm{OH}) \mathrm{D} 3)$ levels, histopathological changes in minor salivary gland biopsy samples and radiological findings were retrieved. RTA was diagnosed in cases of hyperchloremic metabolic acidosis with urinary $\mathrm{pH}$ values higher than 5.5. Those with known features suggestive of RTA including hypokalemic paralysis, hyperchloremia and nephrocalcinosis without acidosis were defined as incomplete RTA.

Results: Of the 380 patients with clinically suspected pSS, 25 had RTA. The median age was 32 (18-60) years. Nineteen patients had complete RTA. Six had incomplete RTA. Only 10 patients (40\%) had symptoms related to RTA at presentation. Sixteen patients $(64 \%)$ had present or past history of hypokalemic paralysis. Pseudofractures were seen in 7 patients and an additional 2 had subclinical radiological osteomalacia. Majority of the patients (61.2\%) had a normal 25(OH) D3 level. Those with osteomalacia had significantly lower serum phosphate, blood ph and higher alkaline phosphatase. Serum calcium and $25(\mathrm{OH})$ D3 levels were not significantly different between patients with osteomalacia and those without.

Conclusion: Most patients were asymptomatic for RTA inspite of clinically overt and elicitable features. Skeletal manifestation was a common finding in patients with Sjögren and RTA, despite normal levels of $25(\mathrm{OH})$ D3 in a majority.
\end{abstract}

Keywords: Osteomalacia, Pseudofractures, Renal Tubular Acidosis, Sjögren’s syndrome, Vitamin D.

\section{INTRODUCTION}

Primary Sjögren's syndrome (pSS) is an autoimmune disease with protean clinical manifestations [1]. The estimated prevalence of pSS ranges between 0.5 and $2 \%$ in various populations, however it remains undiagnosed in a large majority of patients [2]. Two-third of patients with pSS develop extraglandular manifestations [1]. Overt renal involvement in pSS is uncommon and recent literature estimated a clinically significant involvement in $5 \%$ of cases [3]. Tubular and less commonly, glomerular disease have been reported. Interstitial nephritis is the most commonly reported histopathological abnormality [3, 4]. Other manifestations such as renal tubular acidosis (RTA), nephrocalcinosis, subnephrotic proteinuria and chronic kidney disease are also known to occur [4, 5]. Though distal RTA is a common variety; cases of proximal RTA and

*Address correspondence to this author at the Department of Rheumatology and Clinical Immunology, Christian Medical College and Hospital, Vellore632004, India; Tel: 9790521214; Fax: 91-416-2232035;

E-mail: drsandhya.p123@gmail.com
Fanconi's syndrome in pSS have been described in literature $[6,7]$. Osteomalacia is a known complication of RTA, though this complication in the setting of pSS related RTA has not been studied extensively. There are, however, case reports of this complication in pSS including a few from Indian subcontinent [7-15]. At our tertiary care teaching hospital in South India, we regularly see patients with pSS and diverse extraglandular manifestations. There is no data on prevalence of RTA in pSS in Indian population. This series describes the clinical and laboratory profile of RTA in patients with pSS with a special reference to osteomalacia.

\section{METHODS}

We screened Electronic medical record (EMR) of patients diagnosed or suspected to have pSS between 2003 and 2010, for presence of RTA as its complication. EMR in our institute is in vogue since 2003 and it is a windows based application that uses Visual Studio 6.0 as front end integrated development environments (IDE) and Oracle $11 \mathrm{~g}$ as back end for storing patient information. Patients were classified as pSS if they fulfilled either the American- 
European consensus (AEC) classification criteria or Sjögren's International Collaborative Clinical Alliance (SICCA) preliminary criteria $[16,17]$. Those patients fulfilling only 3 AEC criteria inclusive of either positive anti-Ro/La antibody or histopathological grade III or IV in minor salivary gland biopsy and at the same time not fulfilling 2 out of 3 SICCA criteria were considered as 'incomplete Sjögren syndrome'. Patients fulfilling classification criteria of other connective tissue diseases were excluded from the series. RTA was diagnosed when a patient had documented hyperchloremic metabolic acidosis along with a urinary $\mathrm{pH}$ value exceeding 5.5. Patients having only clinical suggestions of RTA, namely hypokalemic paralysis, hyperchloremia and nephrocalcinosis, without documented acidosis at presentation were defined as "incomplete RTA" by our group.

Clinical presentations including extraglandular features, disease duration, detailed medication history, immunological profile, acid-base and electrolyte status, and radiological findings were retrieved from EMR. Histopathology reports by a dedicated pathologist on labial salivary gland tissue biopsied by us were also noted and Daniel's score of grade III or IV were considered significant as per standard classification guidelines [18]. Objective evidence for ocular involvement as documented by Schirmer's test was also noted. Unstimulated whole salivary flow, parotid sialography, salivary scintigraphy and ocular staining score were not done in any of our patients.

Antibodies to Ro and La were done by commercial ELISA kits (Euroimmun, Lubeck, German) and a value of $>$ $20 \mathrm{Ru} / \mathrm{ml}$ was considered to be positive. Highest interassay coefficients of variation using 30 determinants were $8.5 \%$ and $10 \%$, respectively for anti-Ro and anti-La assays mentioned above. Estimation of 25(OH) D3 levels was done using a chemiluminescence immunoassay (Roche Elecsys). Osteomalacia was diagnosed by presence of radiological features of coarse trabeculae, osteopenia and presence of looser's zone. The study was approved by Institutional Review Board, Christian Medical College, Vellore.

Statistical Analysis: Data is presented as mean (SD) or median (range) values. Statistical analysis was performed using GraphPad Prism 5. Mann-Whitney U test was used for statistical analysis and a $\mathrm{p}$ value $<0.05$ was considered as significant.

\section{RESULTS}

Altogether, there were 380 patients comprising of diagnosed cases as well as strong suspects of pSS during the period 2003-2010 with a female: male ratio of 19: 1 . Twenty five $(6.6 \%)$ of them had RTA in this case series (Table 1) and they were all females. The median age was 32 (18-60) years.

Twenty-one of these 25 patients had fulfilled at least 4 AEC criteria and 3 others had fulfilled the newly proposed SICCA criteria to be classified as pSS. Only one patient did not fulfil either criteria, and was therefore labelled as an 'incomplete Sjögren's (patient number seven in Table 1). This patient had a positive Schirmer's test, high titre anti-Ro and anti-La, but salivary gland histopathology was unavailable as she refused a biopsy. None of our patients had any other alternative diagnosis.

Nineteen of these 25 patients with RTA had complete RTA and the remaining 6 had incomplete RTA as per our definition mentioned above. All the 25 patients with RTA were, however, analysed as a single group in this study. The median duration of symptoms at diagnosis was 36 (range: $0.5-168)$ months. The reasons for patients seeking medical attention in this hospital are depicted in Table 2 . It is noticeable that only 10 patients (nine patients with neuromuscular and one with multiple fractures) had clinical complaints related to RTA. The remaining 15 patients $(60 \%)$ did not have any clinical symptoms of RTA in their initial presentation, even though five of these 15 patients had history of documented hypokalemic paralysis. No other cause for RTA was detected in any of these patients. None of these patients were on any medications including Ayurvedic and herbal products which may cause RTA [19].

Of the 25 patients, RF was tested in 17 and both anti-Ro and anti-La were tested in 22 patients. As depicted in Table 1, anti-Ro and anti-La positivity was seen in $100 \%(22 / 22)$ and $86.36 \%(19 / 22)$ of patients respectively. The mean value of Ro and $\mathrm{La}$ was $198.96 \pm 21.24 \mathrm{Ru} / \mathrm{ml}$ and $156.68 \pm 97.27$ $\mathrm{Ru} / \mathrm{ml}$, respectively. Rheumatoid Factor $(\mathrm{RF})$ was positive in $64.71 \%(11 / 17)$. The median (range) and mean (standard deviation) of RF in these 11 patients were 133 (20-612) and 166.9 (166) kIU/L respectively. ANA positivity was seen in $88 \%(22 / 25)$ in this series. Hypothyroidism was present in $44 \%(11 / 25)$. Graves' disease was not seen in any of the patients.

The mean blood and urine $\mathrm{pH}$ were $7.28 \pm 0.08$ and 6.9 \pm 0.44 respectively. The biochemical profile of these patients is given in Table 3. No patient had $25(\mathrm{OH})$ D3 levels less than $10 \mathrm{ng} / \mathrm{ml}$. Level of $25(\mathrm{OH}) \mathrm{D} 3$ was normal (greater than $20 \mathrm{ng} / \mathrm{ml}$ ) in $61.2 \%$ of our patients.

Pseudofractures were seen in seven patients (28\%) (Figs. $\mathbf{1 A}, \mathbf{2}, \mathbf{3})$ and subclinical radiological osteomalacia alone were noted in 2 more patients. These 9 patients with osteomalacia (including seven with pseudo fractures) had significantly higher alkaline phosphatase $(102,763$ vs 56,274; $\mathrm{p}=0.002)$, but lower phosphorus $(1,3$ vs $1,4.6 \mathrm{p}=0.041)$ and lower blood $\mathrm{pH}(7.15,7.35$ vs 7.15,7.42; $\mathrm{p}=0.027)$ as compared to the remaining 16 patients. There was, however, no difference between them in terms of disease duration $(\mathrm{p}=0.46)$, serum levels of calcium $(\mathrm{p}=0.22)$, chloride $(\mathrm{p}=0.39)$, bicarbonate $(\mathrm{p}=0.22), 25(\mathrm{OH}) \mathrm{D} 3(\mathrm{p}=0.93)$, and urine $\mathrm{pH}$ values $(\mathrm{p}=0.23)$. Two of these seven patients with pseudofractures had shown signs of radiological healing after one year (Fig. 1B) following correction of electrolytes and bicarbonate.

Other renal complications in this series included nephrocalcinosis in 5 patients, chronic kidney disease in 2 , renal stones in 1 patient and proteinuria in 18 patients. Proteinuria was less than 1 gram / 24 hours in 9 patients and it was in the $1 \mathrm{gm}$ to $2 \mathrm{gm} / 24$ hours range in the other 9 patients. Renal biopsy was performed in 6 patients; 3 of them had chronic interstitial nephritis, 2 had mesangial glomerulonephritis and arterionephrosclerosis was reported in 1 patient. 
Table 1. Classification criteria features in 25 patients of primary Sjögren syndrome with renal tubular acidosis.

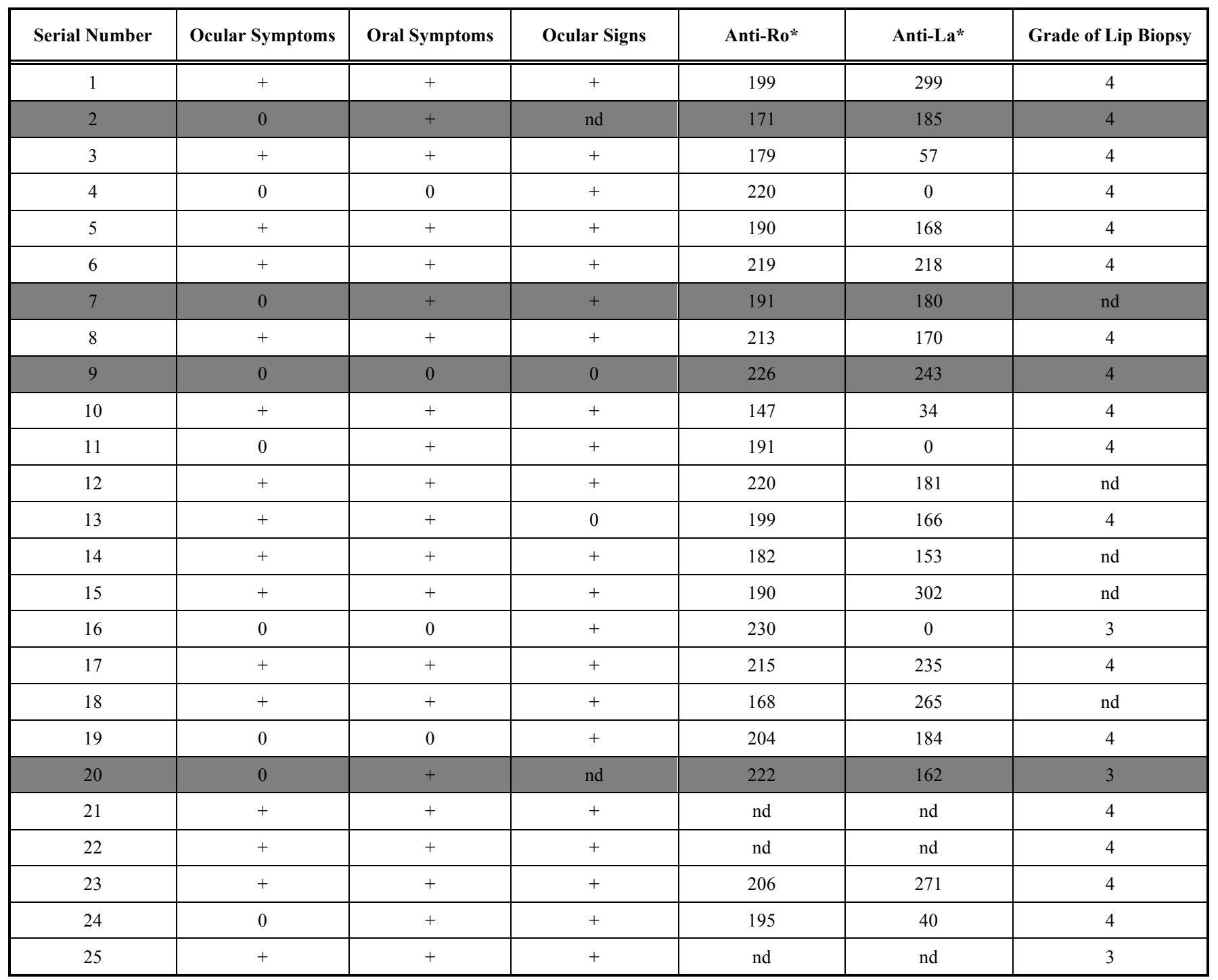

Highlighted rows indicate patients not fulfilling by American-European consensus (AEC) classification criteria. Of these four, with the exception of patient number 7, the remaining three fulfilled Sjögren's International Collaborative Clinical Alliance (SICCA) preliminary criteria. Therefore, patient 7 is considered as a case of 'incomplete Sjögren'.

+ indicates presence of symptoms, 0 indicates absence of symptoms, nd not done.

* cut off $20 \mathrm{Ru} / \mathrm{ml}$

Other extraglandular manifestations of pSS seen in these patients included vasculitis in 4 patients, Monoclonal gammopathy of uncertain significance (MGUS) was present in 3 patients (bone marrow biopsy were normal in these patients); autoimmune hepatitis, autoimmune haemolytic anemia and first degree atrioventricular block was present in 1 patient each. Two patients developed lymphoma during follow up (one of whom had MGUS). In addition to the correction of electrolytes and bicarbonate for RTA, major systemic manifestations of pSS like vasculitis were treated with immunosuppression; minor presentations like musculoskeletal and sicca features were treated with immunomodulators as follows: hydroxychloroquine - 22 patients, glucocorticoids - 8 patients, azathioprine - 2 patients, methotrexate - 2 patients, mycophenolate mofetil 2 patients and cyclophosphamide - 1 patient.

\section{DISCUSSION}

This Indian retrospective case series of patients with RTA in pSS (24 patients fulfilling pSS criteria and 1 of them with 'incomplete Sjögren syndrome) has a few distinctive features.

Firstly, our patients were younger by at least a decade when compared with other series $[1,2]$. These patients had a delay in diagnosis similar to descriptions in literature $[2,20]$. This is not surprising, considering the wide spectrum of the confounding complaints resulting in diversion of most patients to specialities other than rheumatology. The duration of disease prior to diagnosis of our series is similar to that reported in a recent retrospective series of pSS from China with renal disease [21]. Despite having RTA and documented hypokalemic paralysis in the majority of 
Table 2. Primary reason for seeking medical attention in $\mathbf{2 5}$ patients of pSS with RTA.

\begin{tabular}{|c|c|}
\hline Clinical Manifestations & $\begin{array}{l}\text { Number of } \\
\text { Patients }\end{array}$ \\
\hline \multicolumn{2}{|l|}{ General systemic } \\
\hline Fatigue* & 1 \\
\hline \multicolumn{2}{|l|}{ Ocular symptoms } \\
\hline Dry eyes* & 1 \\
\hline Corneal opacity & 1 \\
\hline \multicolumn{2}{|l|}{ Neuromuscular } \\
\hline Acute onset paralysis & 7 \\
\hline Proximal muscle weakness* & 1 \\
\hline Referred as RTA* & 1 \\
\hline \multicolumn{2}{|l|}{ Musculoskeletal / Rheumatological / autoimmune disorders } \\
\hline Multiple fractures* & 1 \\
\hline Polyarthralgia * & 1 \\
\hline Polyarthritis & 2 \\
\hline Referred as SLE & 1 \\
\hline Referred as Sjögren with MGUS & 1 \\
\hline Asymptomatic ANA positivity* & 1 \\
\hline Asymptomatic mother of baby with neonatal lupus & 1 \\
\hline \multicolumn{2}{|l|}{ Hematological } \\
\hline AIHA* & 1 \\
\hline Thrombocytopenia & 1 \\
\hline \multicolumn{2}{|l|}{ Miscellaneous } \\
\hline Deranged LFT* & 1 \\
\hline Parotidomegaly & 1 \\
\hline Irregular cycles with short stature & 1 \\
\hline \multicolumn{2}{|c|}{$\begin{array}{l}\text { * Asterix marked patients }(\mathrm{n}=9) \text { also had past History of hypokalemic paralysis, but not } \\
\text { as their presenting feature. Along with the } 7 \text { patients who presented with this } \\
\text { complication, therefore a total of } 16 \text { patients with hypokalemic paralysis are included } \\
\text { in this series as mentioned in the text. } \\
\text { RTA Renal Tubular Acidosis; pSS Primary Sjögren Syndrome; ANA Anti-nuclear } \\
\text { Antibody; MGUS Monoclonal Gammopathy of Undetermined Significance; AIHA } \\
\text { Autoimmune haemolytic anemia; LFT Liver Function Test. }\end{array}$} \\
\hline
\end{tabular}

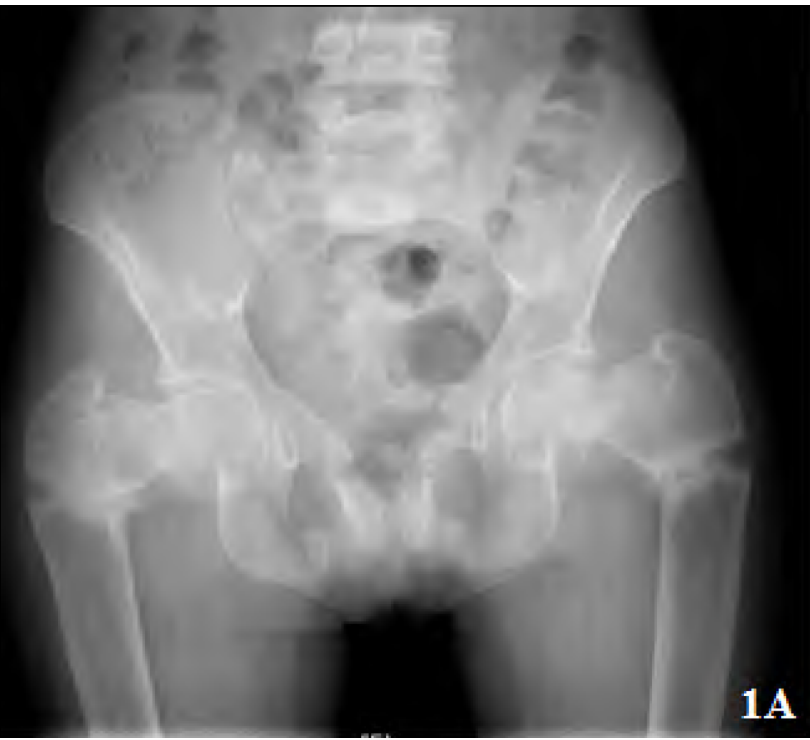

Fig. (1A). Plain radiograph pelvis showing triradiate pelvis and multiple pseudo fracture proximal femur and bilateral pubic ramii.

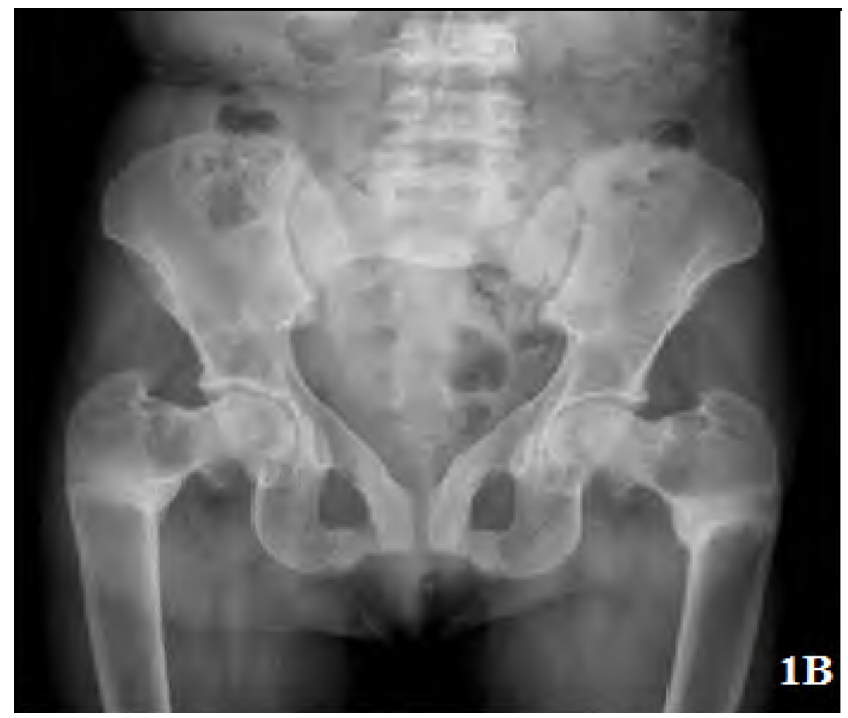

Fig. (1B). Plain radiograph of the same patient 1 year later showing healing of pseudofractures at 1 year.

Table 3. Biochemical Profile of pSS with RTA cohort.

\begin{tabular}{|c|c|c|c|}
\hline Parameter & Number of Patients Tested & Mean \pm SD & Normal Range \\
\hline S. Creatinine $(\mathrm{mg} / \mathrm{dl})$ & 25 & $1.1 \pm 0.343$ & $0.7-1.4$ \\
\hline S. chloride $(\mathrm{mmol} / \mathrm{L})$ & 22 & $116.36 \pm 4.81$ & $95-105$ \\
\hline S. Potassium ${ }^{*}(\mathrm{mmol} / \mathrm{L})$ & 25 & $2.56 \pm 0.87$ & $3.5-5.0$ \\
\hline S. Phosphorus $\ddagger(\mathrm{mg} / \mathrm{dl})$ & 24 & $2.40 \pm 0.82$ & $2.5-4.6$ \\
\hline S. Alkaline phosphatase ${ }^{\S}$ (units/L) & 22 & $196.91 \pm 162.29$ & $40-125$ \\
\hline 25 hydroxy vitamin $\mathrm{D}(\mathrm{ng} / \mathrm{ml})$ & 18 & $27.5 \pm 15.8$ & $20.0-32.0$ \\
\hline
\end{tabular}

* Hypokalemia was present in 21 out of 25 patients

$\dagger \mathrm{S}$. Calcium levels were corrected for albumin. Hypocalcemia was present in 19 out of 24 patients

$\ddagger$, Hypophosphataemia was present in 12 out of 24 patients

${ }^{8}$ High serum alkaline phosphatase was found in 11 out of 22 patients 


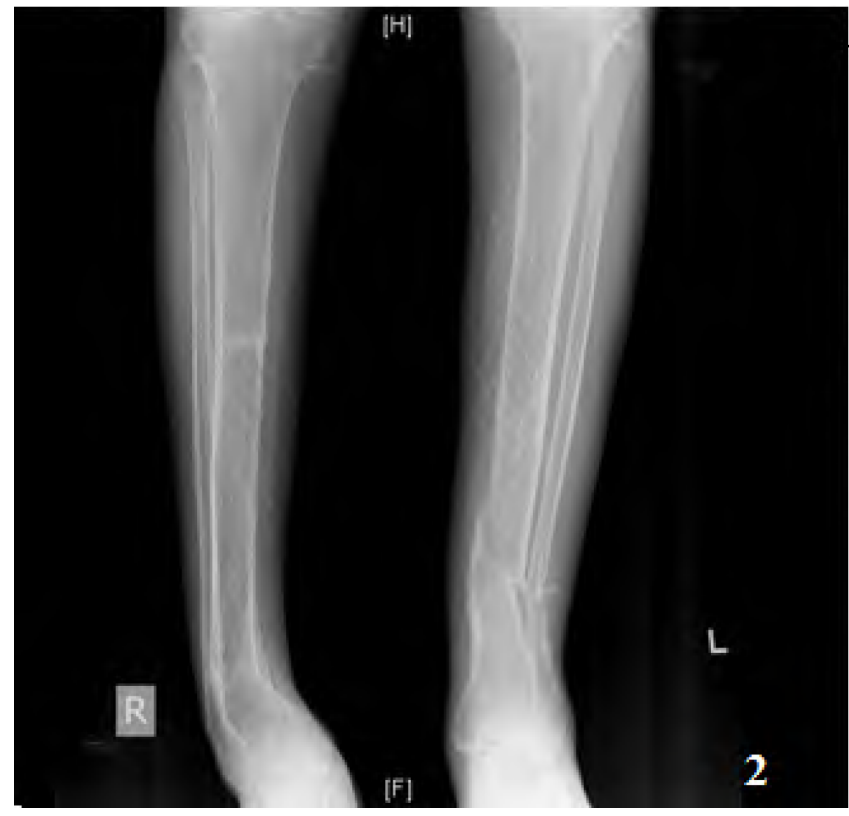

Fig. (2). Plain radiograph showing pseudofractures of right tibia mid and distal, left tibia and fibula.

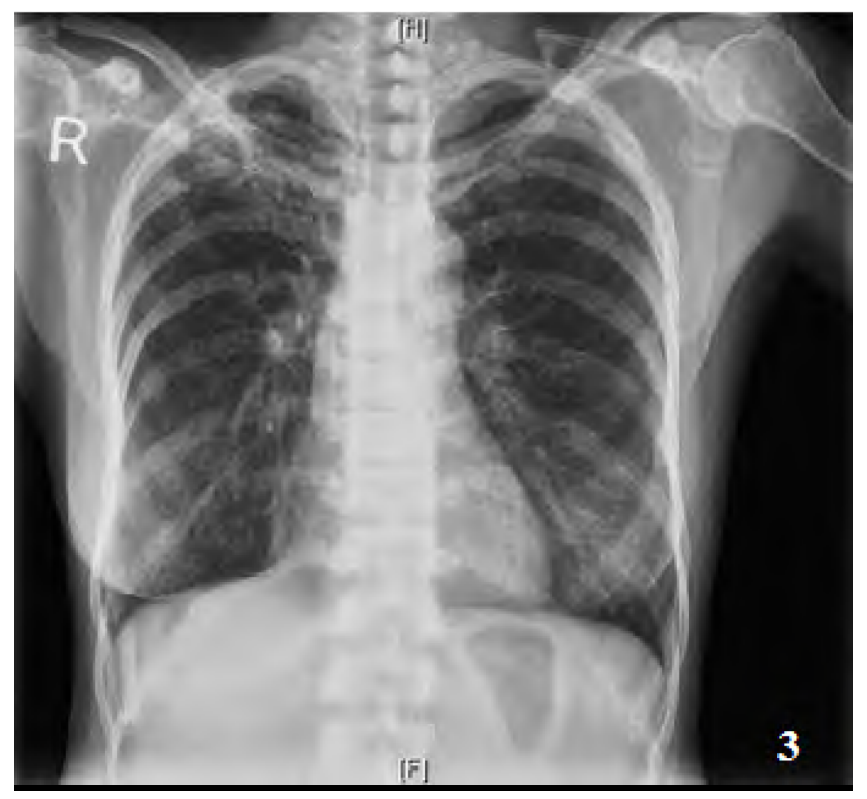

Fig. (3). Plain radiograph showing pseudofracture of neck of scapula on the left.

patients as the commonest presentation, some of them had come to hospital seeking attention for other unrelated complaints. Barring the exception of a single case with a prior referral diagnosis, all the remaining 24 patients were suspected, evaluated and diagnosed as RTA as well as pSS at our centre. We could not attribute any other etiology of RTA to any of our cases in this series.

In another earlier series of 32 patients with hypokalemic paralysis from our centre, RTA was present in 13 of them [22]. Only 3 of these 13 patients with RTA were diagnosed to have primary Sjögren's syndrome. In that series, evaluation for $\mathrm{pSS}$ was done only in those with sicca symptoms or hyperglobulinemia, unlike a proactive search for this problem that was performed in the current series of patients.

Diagnosis of pSS was unequivocal in all our patients excluding one patient refusing biopsy; even, that patient had 3 AEC criteria including high titre anti-Ro and anti-La antibody. This series underscores the importance of evaluating for pSS in patients with RTA, hypokalemic paralysis and osteomalacia, even if the patients do not voluntarily complain of sicca symptoms. In this regard, it is notable that only 2 patients referred by the ophthalmologists (out of the entire series) voluntarily complained of dryness of eyes or mouth, although this history could be elicited on questioning in the majority of them. Paucity of voluntary sicca symptoms in several patients with pSS may imply subclinical systemic autoimmune process preceding overt manifestations.

RTA in pSS was first described in the 1960s [23]. The prevalence of RTA in pSS described in literature varies depending on the methodology of detecting RTA and definition of pSS. Data from 3 recent prospective studies and 2 retrospective studies on renal involvement in $\operatorname{pSS}[5,21$, 24-26] show the frequency of complete RTA (incomplete RTA in parentheses) in Norwegian [24], Finnish [25], Italian [5], American [26] and Chinese [21] patients as $6.45 \%$ (4.8\%), 1.8\% (31.5\%), 5\%, 33.33\% and 73.1\%, respectively. The first case of RTA in pSS from India was described only in 1996 in a patient with repeated episodes of hypokalemic paralysis [27].

In Norwegian, Finnish and Italian studies, either anti-Ro or anti-La positivity was reported in $85.7 \%, 89 \%$ and $100 \%$, respectively $[24,25,5]$, similar to high frequency of anti-Ro $(100 \%)$ and anti-La $(86.6 \%)$ positivity in our series. In the Chinese study, however, anti-Ro and anti-La positivity was found in only $49.5 \%$ and $36.8 \%$, respectively [21].

The prevalence of RTA is $6.6 \%$ in this retrospective case series. Our series represents a select subset of overt RTA with more severe form of $\mathrm{pSS}$; this may be the reason for a higher anti-Ro and anti-La positivity as well as presence of more advanced complications of pSS including lymphoma in 2 of our patients. Association of antibodies to Ro and $\mathrm{La}$ with disease severity and extraglandular manifestations is well known [1].

Most notable feature in this series is the high prevalence of osteomalacia and pseudo fractures. In fact, even these figures of fracture prevalence may be an underestimate, as full skeletal survey was done only in symptomatic patients. There is no data on the prevalence of bone disease in any of the studies quoted above [5, 21, 23-26] and data on skeletal manifestations of RTA in pSS from literature are limited to case reports only. We suggest that pre-emptive detection of RTA in pSS is of utmost importance, as the treatment is simple and rewarding for this significant morbidity.

In spite of restricted mobility in these patients due to proximal myopathy resulting in poor sun exposure, none of 
them had 25(OH) D3 level below $10 \mathrm{ng} / \mathrm{ml}$ and only $38.8 \%$ had levels below $20 \mathrm{ng} / \mathrm{ml}$, the conventional cut off for bone health. None of these patients were on prior high dose Vitamin D supplementation. This is paradoxical as $70 \%$ of healthy Indians [28] and $68 \%$ of our own RA patients [29] had levels below this cut off. Notably, 27\% of our RA cohort had values less than $10 \mathrm{ng} / \mathrm{ml}$ (data not communicated).

Case reports of RTA with osteomalcia in pSS from India also reveal normal $25(\mathrm{OH})$ D3 levels in 2 cases, these patients, however were on prior vitamin $\mathrm{D}$ supplementation $[15,30]$.

What may be the explanation for osteomalacia with surprisingly normal 25(OH) D3 levels? Could a relatively normal to higher vitamin $\mathrm{D}$ level in majority of these patients be analogous to the scenario of vitamin D dependent rickets type I caused by 1-alpha-hydroxylase deficiency? Could damage to renal tubules in RTA cause loss of 1-alphahydroxylase function and hence low 1,25-dihydroxyvitamin $\mathrm{D}$, despite normal 25(OH) D3 ? Considering these possibilities, these patients may need to be supplemented with calcitriol despite normal $25(\mathrm{OH}) \mathrm{D} 3$ levels as practised in vitamin $\mathrm{D}$ dependent rickets type I.

In spite of using stringent diagnostic criteria for pSS, retrospective nature of the study and absence of ammonium chloride loading test to confirm the diagnosis of incomplete RTA were major limitations of our study. Future studies should also include data on 1,25-dihydroxyvitamin D and PTH levels to solve this puzzle.

Finally, we conclude from this retrospective series that Asian Indian cases of RTA in the setting of pSS are diagnosed late in spite of overt hypokalemic periodic paralysis in a vast majority of them. This complication is also associated with a higher prevalence of anti-Ro and antiLo antibody, extraglandular feautures including lymphoma and pseudofractures in spite of normal $25(\mathrm{OH}) \mathrm{D} 3$ levels in $61.2 \%$ of these patients. Similar to proactive search for pSS in RTA, evaluation for RTA in suspected pSS cases including a search for pseudofractures may be meaningful in view of availability of economic and efficacious corrective treatment options.

\section{CONFLICT OF INTEREST}

The authors confirm that this article content has no conflict of interest.

\section{ACKNOWLEDGEMENTS}

Declared none.

\section{REFERENCES}

[1] Ramos-Casals M, Solans R, Rosas J, et al. Primary Sjögren syndrome in Spain: clinical and immunologic expression in 1010 patients. Medicine (Baltimore) 2008; 87: 210-9.

[2] Sánchez-Guerrero J, Pérez-Dosal MR, Cárdenas-Velázquez F, et al. Prevalence of Sjögren's syndrome in ambulatory patients according to the American-European Consensus Group criteria. Rheumatology (Oxford) 2005; 44: 235-240.
[3] Goules AV, Tatouli IP, Moutsopoulos HM, et al. Clinically significant renal involvement in primary Sjögren's syndrome: clinical presentation and outcome. Arthritis Rheum 2013; 65: 294553.

[4] Pokorny G, Sonkodi S, Iványi B, et al. Renal involvement in patients with primary Sjögren's syndrome. Scand J Rheumatol 1989; 18: 231-4.

[5] Bossini N, Savoldi S, Franceschini F, et al. Clinical and morphological features of kidney involvement in primary Sjögren's syndrome. Nephrol Dial Transplant 2001; 16: 2328-36.

[6] Bridoux F, Kyndt X, Abou-Ayache R, et al. Proximal tubular dysfunction in primary Sjögren's syndrome: A clinicopathological study of 2 cases. Clin Nephrol 2004; 61: 434-9.

[7] Yang YS, Peng CH, Sia SK, et al. Acquired hypophosphatemia osteomalacia associated with Fanconi's syndrome in Sjögren's syndrome. Rheumatol Int 2007; 27: 593-7.

[8] Díaz Rodríguez C, González Rivero C, Trinidad San José JC, et al. Osteal complications as first manifestation in a patient with primary Sjögren's Syndrome and with associated distal tubular acidosis (type 1) and chronic renal insufficiency. Ther Apher Dial 2004; 8: 160-3

[9] Pal B, Griffiths ID. Primary Sjögren's syndrome presenting as osteomalacia secondary to renal tubular acidosis. Br J Clin Pract 1988; 42: 436-8.

[10] Hajjaj-Hassouni N, Guedira N, Lazrak N, et al. Osteomalacia as a presenting manifestation of Sjögren's syndrome (abstract). Rev Rhum Engl Ed 1995; 62: 529-32.

[11] Okazaki H, Muto S, Kanai N, et al. A case of primary Sjögren's syndrome presenting as osteomalacia secondary to renal tubular acidosis (abstract). Ryumachi 1991; 31: 45-53.

[12] Okada M, Suzuki K, Hidaka T, et al. Rapid improvement of osteomalacia by treatment in case with sjögren's syndrome, rheumatoid arthritis and renal tubular acidosis type 1. Intern Med 2001; 40: 829-32.

[13] Fulop M, Mackay M. Renal tubular acidosis, Sjögren's syndrome, and bone disease. Arch Intern Med 2004; 164: 905-9.

[14] Marquez-Julio A, Rapoport A, Wilansky DL, et al. Purpura associated with hypergammaglobulinemia, renal tubular acidosis and osteomalacia. Can Med Assoc J 1977; 116: 53-8.

[15] Khandelwal D, Bhattacharya S, Gadodia A, et al. Metabolic bone disease as a presenting manifestation of primary Sjögren's syndrome: Three cases and review of literature. Indian J Endocrinol Metab 2011; 15(4): 341-5.

[16] Vitali C, Bombardieri S, Jonsson R, et al. Classification criteria for Sjo"gren's syndrome: a revised version of the European criteria proposed by the American-European Consensus Group (review). Ann Rheum Dis 2002; 61: 554-558.

[17] Shiboski SC, Shiboski CH, Criswell L, et al. Sjögren's International Collaborative Clinical Alliance (SICCA) Research Groups. American College of Rheumatology classification criteria for Sjögren's syndrome: a data-driven, expert consensus approach in the Sjögren's International Collaborative Clinical Alliance cohort. Arthritis Care Res (Hoboken) 2012; 64: 475-87.

[18] Fox RI, Robinson CA, Curd JG, et al. Sjögren's syndrome: proposed criteria for classification. Arthritis Rheum 1986; 29: 57785.

[19] Chen W, Chen Y, Li A. The clinical and pathological manifestations of aristolochic acid nephropathy--the report of 58 cases. Zhonghua Yi Xue Za Zhi 2001; 81: 1101-5. (Chinese)

[20] Kassan SS, Moutsopoulos HM. Clinical manifestations and early diagnosis of Sjögren syndrome (review). Arch Intern Med 2004; 164: 1275-84.

[21] Ren H, Wang WM, Chen XN, et al. Renal involvement and followup of 130 patients with primary Sjögren's syndrome. J Rheumatol 2008; 35: 278-84.

[22] Rao N, John M, Thomas N, et al. Aetiological, clinical and metabolic profile of hypokalemic periodic paralysis: A singlecentre experience. Natl Med J Ind 2006; 19: 246-249.

[23] Talal N, Zisman E, Schur PH. Renal tubular acidosis, glomerulonephritis and immunologic factors in Sjögren's syndrome. Arthritis Rheum 1968; 11: 774-86.

[24] Aasarød K, Haga HJ, Berg KJ, et al. Renal involvement in primary Sjögren's syndrome. QJM 2000; 93: 297-304. 
[25] Pertovaara M, Korpela M, Kouri T, et al. The occurrence of renal involvement in primary Sjögren's syndrome: a study of 78 patients. Rheumatology (Oxford) 1999; 38(11): 1113-20.

[26] Maripuri S, Grande JP, Osborn TG, et al. Renal involvement in primary Sjögren's syndrome: a clinicopathologic study. Clin J Am Soc Nephrol 2009; 4: 1423-31.

[27] Thomas N, Banumathy R, Seshadri MS. Hypokalemic Periodic Paralysis: An unusual cause. J Assoc Phys Ind 1996; 44: 207-8.
[28] Shivane VK, Sarathi V, Bandgar T, et al. High prevalence of hypovitaminosis $\mathrm{D}$ in young healthy adults from the western part of India. Postgrad Med J 2011; 87: 514-8.

[29] Gopinath K, Danda D. Supplementation of 1,25 dihydroxy vitamin D3 in patients with treatment naive early rheumatoid arthritis: a randomised controlled trial. Int J Rheum Dis 2011; 14: 332-9.

[30] Ramachandiran N. Apparently persistent weakness after recurrent hypokalemic paralysis: a tale of two disorders. South Med J 2008; 101: $940-2$.

Received: July 14, 2014

Revised: October 21, 2014

Accepted: November 3, 2014

(c) Sandhya et al.; Licensee Bentham Open.

This is an open access article licensed under the terms of the Creative Commons Attribution Non-Commercial License (http://creativecommons.org/licenses/by-nc/ $3.0 /$ ) which permits unrestricted, non-commercial use, distribution and reproduction in any medium, provided the work is properly cited. 